Rev. Bras. Saúde Prod. Anim., Salvador, v.15, n.4, p.970-982 out./dez., 2014 http://www.rbspa.ufba.br ISSN 15199940

\title{
Fluxo do transporte de suínos para abate no Estado de Mato Grosso
}

\author{
Flow transport of pigs for slaughter in the State of MatoGrosso
}

\author{
PEREIRA, Thuanny Lúcia ${ }^{1 *}$, CORASSA, Anderson ${ }^{2}$
}

\begin{abstract}
${ }^{1}$ Universidade Federal de Mato Grosso, Instituto de Ciências Agrárias e Ambientais, Programa de PósGraduação em Zootecnia, Sinop, Mato Grosso, Brasil.

${ }^{2}$ Universidade Federal de Mato Grosso, Instituto de Ciências Agrárias e Ambientais, Departamento de Zootecnia, Sinop, Mato Grosso, Brasil.

*Endereço para correspondência: thuanny3@ hotmail.com
\end{abstract}

\section{RESUMO}

Objetivou-se descrever o fluxo de suínos para abate produzidos no Estado de Mato Grosso entre os anos de 2008 e 2012. Foram utilizados dados de 9.426.729 suínos produzidos no Estado de Mato Grosso e transportados para abate de janeiro de 2008 a dezembro de 2012, no qual realizou-se análise descritiva das informações, com frequências de origem e destino; machos e fêmeas em função dos meses e anos e as distâncias percorridas. Observou-se crescimento no número de viagens e de suínos transportados do Estado de Mato Grosso, com valores médios de 19,83 e $19,61 \%$ no período avaliado, respectivamente. Registou-se uma variação de 142,73 a 147,42 de suínos transportados por viagem. As frequências de transporte a distâncias inferiores à200 km aumentaram, enquanto a frequência acima de $500 \mathrm{~km}$ reduziram. Portanto, conclui que ao longo dos anos houve alterações quanto ao volume de animais, distância e percursos, no qual, aumentou o volume de suínos transportados, reduziu o volume de suínos transportados a longa distância, e houve implantação de unidades frigoríficas mais próximas ao local de produção. Desta forma, $73,47 \%$ dos suínos para abate transportados percorreram entre zero e $200 \mathrm{~km}$ da origem ao destino, e a média ponderada de distânciafoi de $205,74 \mathrm{~km}$.

Palavras-chave: distância, frequências, préabate, trânsito

\section{SUMMARY}

We aimed to describe the flow of slaughter pigs produced in MatoGrossobetween 2008 and 2012. We used data 9.426 .729 of pork produced in MatoGrosso and transported for slaughter from January 2008 to December 2012, which conducted a descriptive analysis of the information, with frequencies of origin and destination; males and females in terms of months and years and the distances traveled. There was growth in the number of trips and pigs transported the State of MatoGrosso, with average values of 19.83 and $19.61 \%$ in the study period, respectively. There was a variation from 142.73 to 147.42 of pigs transported per trip. The frequencies of the lower transport distances increased to $200 \mathrm{~km}$, while reducing the frequency of those up to $500 \mathrm{~km}$. Therefore concludes that long of years there have been changes on the volume of animals, distance and routes, which, increased the volume of transported pigs, reduced the volume of pigs transported long distances, and there was installation of plant closest to the production of pigs. Thus, $73.47 \%$ of pigs transported to slaughter traveled between zero and $200 \mathrm{~km}$ from origin to destination, and the average distance was $205.74 \mathrm{~km}$.

Keywords: distance, frequency, pre-slaughter, transit 


\section{INTRODUÇÃOO}

O Mato Grosso apresenta-se como quinto maior estado brasileiro na produção de carne suína (ABIPECS, 2013), devido, entre outros fatores, à enorme extensão territorial, vasta produção de grãos e aos investimentos realizados por empresas privadas. Contudo, alguns fatores ainda limitam a produção, como o predomínio de temperaturas elevadas (OCHOVE et al., 2010), infra-estrutura rodoviária e as longas distâncias observadas entre as unidades de produção e os frigoríficos. Esse último fator repercute diretamente nas condições de bem-estar animal e por consequência na qualidade de carne (LUDTKE et al., 2012).

O transporte compreende um evento estressante na produção de suínos, devido o caminhão ser um ambiente novo, bem como a necessidade de interação de animais de diferentes grupos, com odores distintos, além dos aspectos relacionados a velocidade do veículo, ruídos, diferentes temperaturas ambientais e vibrações (LUDTKE et al., 2012). Todo suíno enfrentará essa circunstância durante sua vida, contudo, assegurar o bem-estar através de suas liberdades apresenta-se como desafio. $\mathrm{Na}$ produção de suínos, ainda busca-se estabelecer um padrão no manejo préabate, de forma à atender as legislações mas sobretudo, respeitando princípios de bem-estar animal à granja, ao transporte e ao abate, o que implicaria em produtos de melhor qualidade.

Expressivas perdas relacionadas ao transporte foram estimadas através da análise de pesquisas conduzida por Schwartzkopf-Genswein et al. (2012) que evidenciaram que $0,25 \%$ dos suínos produzidos nos Estados Unidos morreram durante o transporte e um adicional de $0,44 \%$ chegaram ao frigorífico com alguma injúria, que repercutiram em US\$ 3 milhões de prejuízo em 2010, enquanto no Canadá aproximadamente 17.000 suínos por ano morrem antes à chegada do frigorífico.

Considerando o abatede 31,9 milhões de cabeças de suínos no Brasil em 2013 (ABIPECS, 2013) e a elevada extensão territorial do estado de Mato Grosso, em que na região de Sinop - MT, observouse percursos da unidade de produção a indústria frigorífica que variaram de 34 a330 km, com média de 167,85 km de percurso (CORASSA et al., 2013) estima-se um grande impacto da distância no transporte pré-abate, no entanto, estas não são conhecidas.

Dessa forma, o objetivo dessa análise foi descrever o fluxo de suínos destinados ao abate produzidos no Estado de Mato Grosso entre os anos de 2008 e 2012.

\section{MATERIAL E MÉTODOS}

O estudo foi realizado com dados de 9.426.761 suínos produzidos no Estado de Mato Grosso e transportados para abate de janeiro de 2008 a dezembro de 2012 fornecidos pelo Instituto de Defesa Agropecuária do Estado de Mato Grosso (INDEA-MT). A base de dados dispunha do número da Guia de Trânsito Animal (GTA), número de suínos machos e fêmeas por documento e local de origem e destino dos animais, totalizando 64.942 episódios de transporte.

A partir do banco de dados realizou-se análise descritiva das informações, analisando-se as frequências de origem e destino, machos e fêmeas em função dos meses e anos. Para caracterização das distâncias percorridas pelos veículos de transporte, realizaram-se simulações 
entre origem e destino através do Guia Rodoviário Quatro Rodas (ABRIL, 2013), considerando-se o centro geodésico do município como ponto de partida e chegada e a rota mais rápida possível entre estes.

Os dados foram submetidos à análise estatística descritiva com base na distribuição de frequências relativas utilizando-se o programa SAEG (UFV, 1999).

\section{RESULTADOS E DISCUSSÃO}

O total de suínos abatidos produzidos no Estado de Mato Grosso observado neste levantamento ao longo dos anos avaliados apresentou aumento médio de $19,61 \%$, com destaque à variação de $37,60 \%$ ocorrida entre 2009 e 2008 e de $100,62 \%$ de 2008 a 2012 (Tabela 1). Contudo, os valores diferem daqueles apresentado pela ABIPECS (2013) que, ao considerar a produção industrial do estado registrou abates de 1,686; 1,835; 2,084; 2,226 e 2,556 milhões de suínos de 2008 a 2012, entretanto, com variações similares aos do presente estudo. De forma similar, observou-se aumento no número de viagens dos suínos das granjas aos abatedouros ou frigoríficos, apresentando crescimento médio anual de $19,83 \%$ no período estudado (Tabela 1).

O aumento no número de viagens é consequiência do aumento de produção observado ao longo dos anos, contudo, implica no aumento dos custos de produção da cadeia relacionados à combustível, depreciação, juros, impostos, seguro automotivo, salários, manutenção, além do custo ambiental e com acidentes (RONCHI et al., 2013), e da incidência de mortalidade e anormalidades na carne (DALLA COSTA et al., 2010).

Tabela 1. Número de suínos machos castrados e fêmeas transportados à partir do Estado de Mato Grosso e a média por viagem de 2008 a 2012

\begin{tabular}{cccccccc}
\hline Ano & Viagens & $\begin{array}{c}\text { Crescimento em } \\
\text { relação ao ano } \\
\text { anterior (\%) }\end{array}$ & $\begin{array}{c}\text { Animais } \\
\text { por } \\
\text { viagem }\end{array}$ & Fêmeas & $\begin{array}{c}\text { Machos } \\
\text { Castrados }\end{array}$ & Total & $\begin{array}{c}\text { Crescimento em } \\
\text { relação ao ano } \\
\text { anterior (\%) }\end{array}$ \\
\hline 2008 & 8.021 & - & 147,32 & 597.747 & 583.924 & 1.181 .671 & - \\
2009 & 11.392 & 42,03 & 142,73 & 826.117 & 799.824 & 1.625 .941 & 37,60 \\
2010 & 13.792 & 21,07 & 143,88 & 1.001 .930 & 982.419 & 1.984 .349 & 22,04 \\
2011 & 15.655 & 13,51 & 144,63 & 1.134 .568 & 1.129 .546 & 2.264 .114 & 14,10 \\
2012 & 16.081 & 2,72 & 147,42 & 1.191 .547 & 1.179 .107 & 2.370 .654 & 4,71 \\
Total & 64.941 & - & - & 4.751 .909 & 4.674 .820 & 9.426 .729 & - \\
\hline
\end{tabular}

A adequação dos veículos transportadores quanto à capacidade de carga, às características construtivas e ao tempo de uso, assim como a melhoria da logística de transporte, poderia minimizar este impacto através do maior número de animais por viagem. Segundo Machado et al. (2014) o tempo de embarque, velocidade do veículo e tempo de descanso exercem relação direta sobre incidência de carne pálida, flácida e exsudativa, sugerindo adequação da logística de transporte.

Contudo, o presente estudo caracterizou que houve pouca variação no número de animais transportados por viagem, de 142,73 a 147,42 suínos por evento no período avaliado. Tais valores 
apresentaram-se maiores quando comparados ao estudo de Dalla Costa et al. (2010) em que os transportes ocorreram com 96 suínos e Corassa et al. (2013) que registraram valores entre 91 e 120 suínos por viagem em um levantamento realizado no próprio estado de Mato Grosso. No entanto, o número médio de suínos por viagem foi abaixo daqueles considerados por Ochove et al. (2010) registrando média de 200 suínos a cada viagem considerando o mesmo estado, enquanto levantamentos nos Estados Unidos da América, realizados por Kephart et al. (2010) registraram médias de $166 \mathrm{e}$ 170 suínos por viagem ao considerarem 2.053.945 e 41.744 suínos, respectivamente em suas pesquisas.

A variação de dados quanto ao transporte está vinculado a aspectos como falta de legislação quanto a densidade adequada de transporte de suínos no Brasil, associado a isso, a logística de indústrias frigoríficas que visam "otimizar" o transporte, ao maximizar o número de suínos em um determinado veículo, e reduzir o número de viagens. Diante desse fato, existe a necessidade de estudos referentes a transporte de suínos no intuito de determinar a densidade adequada de acordo com o clima regional.

Mesmo assim, pondera-se que possivelmente houve aumento do peso de abate dos suínos ao longo dos anos, implicando em maior quantitativo de carga total por viagem. É possível realizar esta inferência com base na evolução dos pesos médios das carcaças no Brasil de 2009 a 2011, que foram 85,91; 86,25 e $88,21 \mathrm{Kg}$, respectivamente (ABIPECS, 2013). Essa caracterização de maior carga por viagem, de alguma forma pode ser associado com a elevação da capacidade dos veículos, que passaram a ter entre dois ou três eixos e com capacidade máxima de carga de aproximadamente
14 toneladas, ou carretas que são veículos compostos por cabine com seus equipamentos de tração (cavalo mecânico) e o semi-reboque (carroceria), que podem apresentar capacidade estimada de 30 toneladas (KEEDI, 2011). Assim, ao relacionar-se número de animais por viagem, área por animal e capacidade de carga do veículo transportador, caracteriza-se a densidade animal ao transporte pré-abate, tratandose de um fator que tem impacto direto na logística, no bem estar animal e na qualidade de carne. Pesquisas apontam que densidade inadequada no transporte pode resultar em lesões na pele, interferir nos parâmetros da qualidade da carne (CHAI et al., 2010), nos constituintes sanguíneos, mortalidade durante o percurso e alterações comportamentais e fisiológicas (SUTHERLAND et al., 2009). A diretiva de proteção animal European Comission (EC, 2005) recomenda que a densidade de transporte deve ser de $0,425 \mathrm{~m}^{2} / 100 \mathrm{~kg}$ de suínos ou $235 \mathrm{Kg} / \mathrm{m}^{2}$, entretanto, não há legislação especifica no Brasil, e há carência de pesquisas aplicadas às condições do país.

A proporção de suínos fêmeas transportados para abate foi maior que a de machos castrados em todos os anos analisado, apresentando crescimento médio anual de 19,44 e $19,79 \%$ no período estudado, respectivamente. Essa variação pode ser decorrente do trauma de castração, manejo que pode acarretar a ocorrência de redução no ganho de peso, tornando-os predispostos a infecções secundárias, bem como interferindo no desempenho subsequente. Contudo, Herrera et al. (2010) em estudo realizado com períodos de transportes de 8 e 16 horas observaram que as fêmeas foram mais susceptíveis ao estresse durante o transporte que os machos castrados, por apresentar acidose, hipocapnia, hipóxia, hipercalcemia, hipernatremia, maiores 
níveis de glicose, acréscimo no níveis de lactato e no hematócrito.

A maior parte dos suínos produzidos em Mato Grosso foi destinada ao abate no próprio Estado, com valor médio de $94,54 \%$ do número total (Tabela 2). Este valor sugeriria inicialmente a condição de que os transportes seriam realizados em distancias menores. Porém, deve se considerar que viagens realizadas no próprio estado não remetem, necessariamente à percursos breves, conforme dados citados na tabela 4 .

Tabela 2. Número e percentual de suínos para abate produzidos no Estado de Mato Grosso e transportados por estado de destino de 2008 a 2012

\begin{tabular}{|c|c|c|c|c|c|c|}
\hline \multirow{2}{*}{ Estado } & 2008 & 2009 & 2010 & 2011 & 2012 & \multirow{2}{*}{$\begin{array}{c}\text { Média } \\
(\%)\end{array}$} \\
\hline & $\mathrm{N}$ & $\mathrm{N}$ & $\mathrm{N}$ & $\mathrm{N}$ & $\mathrm{N}$ & \\
\hline DF & 5.696 & 12.382 & 16.139 & 22.574 & 19.266 & 0,77 \\
\hline GO & 23.310 & 29.551 & 56.473 & 47.294 & 36.605 & 2,05 \\
\hline MG & 178 & 18.487 & 980 & 828 & 4.770 & 0,29 \\
\hline MS & 25.800 & 6.199 & 500 & 22.216 & 52.052 & 1,15 \\
\hline MT & 1.099 .689 & 1.540 .713 & 1.890 .064 & 2.155 .978 & 2.237 .555 & 94,54 \\
\hline PR & 6.883 & 943 & 1.731 & 3.228 & 4.863 & 0,22 \\
\hline RO & 584 & 79 & 0 & 896 & 10.372 & 0,11 \\
\hline $\mathrm{SC}$ & 0 & 0 & 875 & 0 & 0 & 0,01 \\
\hline SP & 19.531 & 17.587 & 16.908 & 6.877 & 552 & 0,78 \\
\hline TO & 0 & 0 & 679 & 2.309 & 1.210 & 0,04 \\
\hline Outros & 0 & 0 & 0 & 1.914 & 3.409 & 0,05 \\
\hline TOTAL & 1.181 .671 & 1.625 .941 & 1.984 .349 & 2.264 .114 & 2.370 .654 & 100 \\
\hline
\end{tabular}

O segundo destino mais importante foi o Estado de Goiás, respondendo por $2,05 \%$ de todos os suínos de abate. O Estado de Mato Grosso do Sul apresentou-se como terceiro maior destino dos suínos produzidos em Mato Grosso com $1,15 \%$ dos animais transportados. A variação no número de suínos transportados em cada um dos estados, ao longo dos anos avaliados, pode estar relacionado aos preços praticados, à elevada demanda de abate para mercados específicos como a exportação, bem como as limitações ou exigências sanitárias de cada estado. Obviamente a proximidade geográfica justifica a grande proporção de suínos transportados aos estados limítrofes ao estado de origem.

Constatou-se número de suínos destinados ao abate transportados no
Estado de Mato Grosso apresentando crescimento de 40,10;22,67; 14,07 e $3,78 \%$ de 2009 a 2012 em relação ao ano anterior. $\mathrm{O}$ abate de suínos no Brasil foi de 26.096.432 no ano de 2008 e 32.262.355 no ano de 2012, o que demonstrou um crescimento de $23,63 \%$ de abate de suínos no Brasil (ABIPECS, 2013). Pode-se então definir que no ano de 2012, o Estado do Mato Grosso abateu $6,94 \%$ dos suínos em relação ao total de abatidos.

Ao analisar os dados de transporte de suínos entre 2008 e 2012, observou-se a tendência de aumento das frequências de transporte à distâncias inferiores à $200 \mathrm{~km}$, enquanto a frequência daqueles acima de $500 \mathrm{~km}$ tenderam a diminuir (Tabela 3). Frequências mais elevadas nas maiores distâncias nos anos iniciais do levantamento retratam uma condição 
de pequeno número de abatedouros no estado. No ano de 2008, a maior parte dos destinos concentraram-se nas distâncias de 100 a 200 km com percentual de $34,70 \%$, diferentemente dos anos de 2009, 2010, 2011 e 2012 na qual a maior parte dos destinos ficaram entre às distâncias de 50 a 100 km com percentual de 23,$73 ; 34,99 ; 42,55$ e $42,17 \%$, respectivamente. Esta constatação pode estar relacionada à expansão da suinocultura como um todo, e de forma direta à instalação de abatedouros e ao aumento de unidades de produção de suínos próximos à estes, fazendo com que a distância percorrida no pré-abate diminuísse.

Tabela 3. Distribuição percentual de suínos destinados ao abate produzidos no Estado de Mato Grosso em função das distâncias de origem-destino nos anos de 2008 a 2012

\begin{tabular}{lccccc}
\hline \multicolumn{7}{c}{ Animais } & \multicolumn{7}{l}{ ransportados por distância $(\%)$} & \\
\hline Distância $(\mathrm{km})$ & 2008 & 2009 & 2010 & 2011 & 2012 \\
\hline$>2000$ & 0,01 & 0,27 & 0,40 & 0,25 & 0,18 \\
1000 a 2000 & 2,97 & 4,46 & 3,53 & 2,96 & 2,67 \\
500 a 1000 & 7,29 & 9,81 & 9,65 & 4,58 & 3,02 \\
400 a 500 & 17,85 & 13,60 & 7,06 & 7,77 & 9,14 \\
300 a 400 & 1,16 & 0,62 & 0,74 & 0,66 & 1,51 \\
200 a 300 & 4,20 & 5,10 & 5,58 & 3,70 & 1,94 \\
100 a 200 & 34,70 & 21,86 & 17,10 & 15,34 & 16,79 \\
50 a 100 & 12,12 & 23,73 & 34,99 & 42,55 & 42,17 \\
0 a 50 & 19,70 & 20,56 & 20,95 & 22,19 & 22,57 \\
\hline Total & 100 & 100 & 100 & 100 & 100 \\
\hline
\end{tabular}

Registrou-se uma redução no percentual de 17,$85 ; 13,60 ; 7,06 ; 7,77 ; 9,14 \%$ na distância de 400 a 500 Km, respectivamente, em função das distâncias de origem e destino entre 2008 a 2012. Essa informação está relacionada a variação no volume de animais transportados pelos trajetos entre Campo Verde a São Gabriel do Oeste (MS) e Tangará da Serra a Rondonópolis (MT) no período avaliado.SchwartzkopfGenswein et al. (2012) relataram que suínos transportados 30 minutos, foram mais difíceis de manejar e produzir carne do tipo pálida, flácida e exsudativa, bem como, animais transportados em períodos superiores a 2 horas apresentaram estresse prolongado com efeito no desvio de qualidade de carne escura, firme e seca.
Considerando os percursos observados e a proporção de animais em cada trecho, observou-se que os animais para abate foram transportados em distâncias médias ponderadas de 247,82; 256,29; 218,$58 ; 176,82$ e $166,97 \mathrm{~km}$, para os anos de 2008; 2009; 2010; 2011 e 2012, respectivamente, com média geral de $205,74 \mathrm{~km}$. Os valores das distancias médias observadas em 2011 e 2012 são próximos daquele encontrado por Corassa et al. (2013) que, nos mesmos anos, reportaram um percurso médio de $167,85 \mathrm{~km}$ em uma região do Estado de Mato Grosso. Nesse sentido, os autores enfatizam que o conhecimento do percurso é de grande importância, principalmente em rodovias não pavimentadas devido à dificuldade dos suínos para manter o equilíbrio, devido 
à vibração da carroceria do caminhão, que caracteriza um aspecto do movimento com direção horizontal ou vertical, aceleração e frequência; e em função da duração e intensidade de impactos a que os suínos são submetidos.

A preocupação com o transporte de suínos por curtas ou longas distâncias está baseada no impacto deste evento sobre o bem-estar animal e sobre o produto final. Segundo Werner et al. (2007), distancias percorridas em tempo superior a oito horas ou inferiores a uma hora afetam negativamente o bem estar animal ocasionando maiores taxas de mortalidade.

As viagens curtas tendem a prejudicar o animal, pois o submetem a um tempo muito breve de adaptação aos fatores estressantes, fazendo com que boa parte destes estejam cansados (OCHOVE et al., 2010), ou em situação de estresse no momento do desembarque em relação àqueles transportados por longas distancias em que há tempo suficiente para a recuperação dos parâmetros fisiológicos (AVERÓS et al., 2007). Segundo Bryer et al., (2011), a maior ocorrência de mortalidade e de animais com dificuldade de locomoção acontecem nas primeiras horas de transporte. Em viagens curtas, a principal causa de perda de peso esta relacionada a excreção de urina e fezes (GONZÁLEZ et al., 2006).

Porém, a maior preocupação tende a ser com as maiores distancias que, por consequência sugerem maior tempo de transporte, por submeter o animal à condição de desconforto por um período maior. González et al. (2006) registraram maior percentual de mortalidade no transporte $(0,46 \%)$, e maior perda de peso $(1,36 \mathrm{~kg})$, quando os suínos foram submetidos a transportes superiores a $100 \mathrm{~km}$, em comparação àqueles $(0,21 \%$ e $1,06 \mathrm{~kg}$, respectivamente) transportados a menos de $50 \mathrm{~km}$ de distância.

Embora a maior frequência de transporte de suínos para abate esteja nas faixas de até $100 \mathrm{~km}$ (Figura 1) compreendendo 52,31\%, há uma proporção expressiva $(47,69 \%)$ de suínos sendo transportados acima desta distância, sendo que 26,53\% dos animais foram transportados em distancias superiores a $200 \mathrm{~km}$. A distancia percorrida no pré-abate de suínos influencia na qualidade de carne, como observado por Ochove et al. (2010) ao avaliar as distâncias de 45, 430 e $700 \mathrm{~km}$ entre granja e frigorífico em Mato Grosso e quando constataram que os animais transportados a uma distância de $430 \mathrm{~km}$ obtiveram menores valores de $\mathrm{pH}$ em comparação com as demais distâncias, porém dentro da faixa de normalidade para carnes normais $(\geq 5,5)$.

Percursos longos podem apresentar efeito na qualidade da carne, relacionado a uma depleção de energia em suínos desidratados como carne do tipo escura, firme e seca (MOTA ROJAS et al., 2006) ou pálida, flácida e exsudativa (AVERÓS et al., 2007). Os dados de Bryer et al. (2011) registraram que em períodos de transporte superior a 30 horas os suínos transportados apresentaram uma experiência de estresse agudo e alterações na homeostase provavelmente relacionadas com a desidratação, privação de alimento e do acondicionamento no transporte. Em geral, quanto mais longa a viagem, os suínos tendem a ficar mais cansados, existe a necessidade de água e comida, sendo afetado por qualquer condição adversa, maior a imunossupressão, suscetíveis à doença e às vezes mais expostos a agentes patogênicos (BROOM, 2008). 


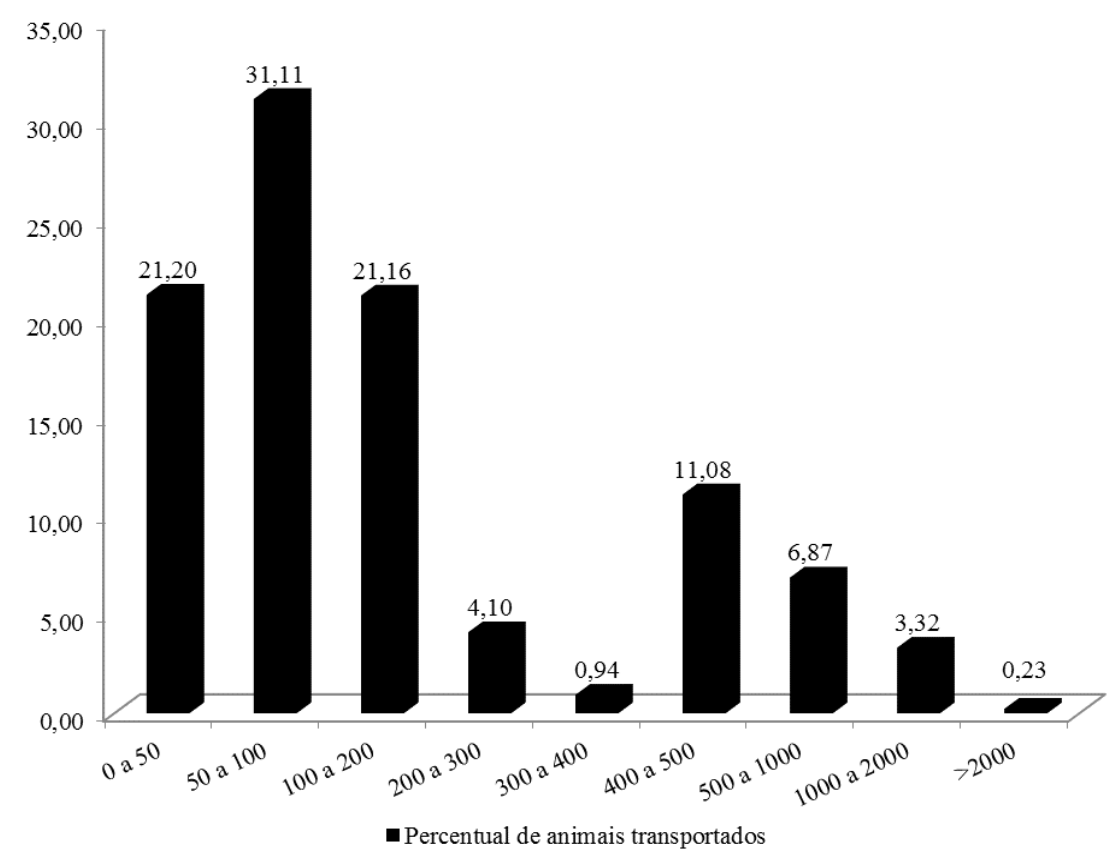

Figura 1. Frequência média (\%) de suínos destinados ao abate produzidos no Estado de Mato Grosso em função das distâncias de origem-destino entre 2008 e 2012

Haley et al. (2008) reportaram que com o aumento da distância de 280 para $475 \mathrm{~km}$ refletiu em acréscimo na mortalidade no transporte de 0,21 a $0,28 \%$, respectivamente. Posteriormente, Sutherland et al. (2009) observaram elevação no percentual de suínos mortos na chegada a indústria frigorífica quando aumentou a duração do transporte de 30 minutos para 4 horas. A maior ocorrência de mortalidade em suínos transportados por longas distancias pode estar relacionado a síndrome do estresse dos suínos, uma reação aguda, mediado pelo sistema nervoso simpático que pode resultar na morte do animal. Os sinais clínicos apresentados pelos animais afetados são dispnéia, cianose e hipertermia além da presença de rigor muscular antes que a morte ocorra (OCHOVE et al., 2010). Em longas distâncias os suínos são fisicamente muito exigidos quando permanecem a maior parte em pé e tentando manter seu equilíbrio
(GEBRESENBET et al., 2011), além de outros fatores negativos como flutuações de temperaturas, ausência de comida, água e descanso exacerbada por longos períodos (MIRANDA-DE LA LAMA et al., 2014).

Mesmo considerando que a proporção de suínos transportados por mais de $2.000 \mathrm{~km}$ tenha sido abaixo de $0,40 \%$ ao longo do período analisado (Tabela 3), chama a atenção a realização do transporte de suínos em percursos extremamente longos. Chai et al. (2010) correlaciona informações de tempo de transporte longo (5 horas) com maior percentual de perda por gotejamento, alterações no pH final e coloração da carne suína.

Os maiores percursos realizados pelos animais transportados para abate foram de $2.149,2.193 ; 2.199 ; 3.101$ e 2.961 $\mathrm{km}$ nos anos de 2008 a 2012, respectivamente, percorridos entre os municípios de Brasnorte a São Joaquim de Bicas-MG; Brasnorte a Sabará-MG; 
Ipiranga do Norte a Chapecó-SC; Lucas do Rio Verde a Guaiuba-CE e Rondonópolis a Cruz-CE, respectivamente. Há enorme carência de informações sobre as implicações de viagens realizadas com suínos em percursos tão extensos quanto estes citados no presente trabalho, limitando a ponderação dos prejuízos aos animais e à cadeia produtiva. Haley et al. (2008) observaram que a cada aumento de 50 $\mathrm{km}$ de distância no transporte, houve uma redução 0,81 vezes no percentual de mortalidade na chegada e reportaram uma redução na mortalidade no transporte com viagem de distâncias superior a $134 \mathrm{~km}$.

Parece razoável que percursos extremamente longos como os relatados só devam ser realizados quando estritamente necessários e com veículos adequados, paradas para descanso e realimentação dos animais. Diante de longas distâncias as leis de transporte nos Estados Unidos afirmam que os animais não podem ser transportados em períodos superiores a 28 horas sem fornecer alimento e água, com devido descanso (49 U.S.C. § 80502). Por sua vez, a Comissão da União Europeia recomenda que a duração de transporte de suínos para o abate não ultrapasse oito horas, e que em viagens longas os animais sejam desembarcados, descansados por 24 horas e receberam ração antes da continuidade do percurso (EC, 2005).

Contudo, o tempo de transporte longo sob condições de transporte controladas, como adequada densidade, apresenta tempo suficiente para os suínos aclimatarem-se e recuperar-se do estresse do carregamento (WESCHENFELDER et al., 2013), como foi observado por Haley et al. (2008) e Sutherland et al. (2009) com redução na mortalidade no transporte quando se compara curtos versus longos trajetos, e Chai et al.
(2010) que verificaram redução nos níveis de cortisol e lactato, com efeito direto na qualidade da carne.

Além do aspecto distância, deve se considerar que o número de suínos transportados no mesmo veículo, não pode ser o mesmo em curtos ou longos trajetos. Chai et al. (2010) recomendaram que em longos trajetos com altas densidades de lotação devem permitir aos suínos longos períodos de descanso para o restabelecimento do estresse físico, bem como, adequado bem estar e qualidade do produto final.

A partir dos dez principais trajetos de suínos para abate produzidos no Estado de Mato Grosso nos anos de 2008 a 2012 verificou-se o principal trajeto foi de Tapurah a Lucas do Rio Verde, com cerca de $99 \mathrm{~km}$ e representando 15,99\% do total dos suínos transportados (Tabela 4). Isso se deve à instalação do maior parque industrial de abate de aves, suínos e produção de embutidos da America Latina em sistema integrado na cidade de Lucas do Rio Verde que entrou em funcionamento em 2008 (COOAGRIL, 2012).

$\mathrm{O}$ segundo trajeto mais frequente foi no percurso de Diamantino à Rondonópolis, visto que no ano de 2008foi o principal trajeto com $14,02 \%$, e a partir de 2009 a 2012 , segundo $(11,89 \%)$, quinto $(6,40 \%)$, quarto $(7,12 \%)$ e quinto trajeto $(7,39 \%)$, respectivamente. Essa variação de volume de animais transportados pode estar relacionado a criação de novas unidades de produção próximas a planta frigorífica. A distância de $422 \mathrm{~km}$ deste trajeto implica em grande número de animais submetidos à longas distâncias, e retrata trajeto diferente daquele observado por Corassa et al. (2013) ao reportaram que o percurso da granja a unidade frigorífica variou de 34 a 330 $\mathrm{km}$.

Em função do método empregado no presente estudo, os menores percursos 
Rev. Bras. Saúde Prod. Anim., Salvador, v.15, n.4, p.970-982 out./dez., 2014 http://www.rbspa.ufba.br ISSN 15199940

encontrados foram iguais a zero quilometro percorrido, significando que suínos são produzidos e abatidos no mesmo município. Logo, o número de suínos que foram enviados ao abate no mesmo municipio onde foram produzidos explicita que o fator distância entre granja e abatedouro não é determinante para o destino dos animais. Possivelmente o regime de produção na forma de integração ou a melhor valorização comercial pontualmente em um frigorífico poderiam explicar a escolha de determinado trajeto.

Tabela 4. Dez principais trajetos de suínos destinados ao abate produzidos no Estado de Mato Grosso no ano de 2008 a 2012

\begin{tabular}{lcccc}
\hline Origem & Destino & Total & Percentual & $\mathrm{Km}$ \\
\hline Tapurah & Lucas do Rio Verde & 1.507 .685 & 15,99 & 99.18 \\
Diamantino & Rondonópolis & 822.414 & 8,72 & 422.3 \\
Lucas do Rio Verde & Lucas do Rio Verde & 813.443 & 8,63 & 0 \\
Nova Mutum & Nova Mutum & 776.894 & 8,24 & 0 \\
Sorriso & Lucas do Rio Verde & 764.255 & 8,11 & 63.16 \\
Diamantino & Nova Mutum & 378.247 & 4,01 & 123.14 \\
Tapurah & Nova Mutum & 289.461 & 3,07 & 152,01 \\
Vera & Sorriso & 255.944 & 2,72 & 62,24 \\
Nova Mutum & Lucas do Rio Verde & 239.471 & 2,54 & 97,16 \\
Vera & Nova Mutum & 227.314 & 2,41 & 219,49 \\
Outros & - & 3.351 .601 & 35,55 & - \\
\hline Total & & 9.426 .729 & 100,00 & \\
\hline
\end{tabular}

O transporte de suínos para abate em Mato Grosso representou 1.188 .983 suínos transportados a mais no de 2012 em comparação ao de 2008. Os percursos foram realizados com distâncias média ponderada de $205,74 \mathrm{~km}$, sendo a grande maioria, $73,47 \%$ dos suínos para abate transportados percorreram entre zero e $200 \mathrm{~km}$ da origem ao destino.

A maioria $94,54 \%$ dos suínos produzidos no Estado do Mato Grosso são abatidos no próprio estado sendo que o trajeto entre os municípios de Tapurah a Lucas do Rio Verde foi o principal percorrido pelos suínos para abate.

O aumento da suinícola no estado de Mato Grosso nos últimos anos foi expressivo ao ponto de projetar a cadeia produtiva como sistema de produção animal muito intensivo. Contudo, as ocorrências de transporte de suínos pré- abate à longas distancias sugerem custos elevados do ponto de vista biológico, logístico e monetário. Logo, em situações similares à esta, se faz necessário investir em melhorias para preservar o bem estar animal e aumentar os lucros da indústria, melhorando a logística para além da legislação com base em evidencias científicas (MIRANDA-DE LA LAMA et al., 2014).

Além disso, a compreensão total das consequências dos eventos estudados nesta pesquisa sobre o animal e a cadeia produtiva só será possível com a investigação das variáveis envolvidas e a mensuração do seu impacto em função das características particulares da região como: dimensão territorial, clima, distancias entre granjas e abatedouros, condições rodoviárias, tipos de veículos, manejo de embarque e desembarque, 
Rev. Bras. Saúde Prod. Anim., Salvador, v.15, n.4, p.970-982 out./dez., 2014 http://www.rbspa.ufba.br ISSN 15199940

entre outros. Assim, estudos de análise destes fatores devem ser encorajados.

\section{REFERÊNCIAS}

ABIPECS. Estatísticas. Os números das exportações brasileiras de carne suína em 2013 e Produção brasileira de carne suína de 2004 a 2011. São Paulo: Associação Brasileira Ind. Prod. Exp. Carne Suína. Disponível em: $<$ http://www.ABIPECS.org.br/uploads/r elatorios/mercadoexterno/exportacoes/a nuais/jan-set-2013_jan-set-2012.pdf>. Acesso em: 18 abr. 2013.

ABRIL. Guia rodoviário quatro rodas. São Paulo: Abril. Disponível em: $<$ http://viajeaqui.abril.com.br/guia4roda s>. Acessoem: 15 fev. 2013.

AVERÓS, X.; HERRANZ, A.; SANCHEZ, R.; COMELLA, J.X.; GOSALVEZ, L.F. Serum stress parameters in pigs transported to slaughter under commercial conditions in different seasons. Veterinarni Medicina, v.52, n.8, p.333-342, 2007.

BROOM, D.M. The welfare of livestock during road transport. In: APPLEBY, M.; CUSSEN, V.; GARCES, L.; LAMBERT, L.; AND TURNER, J. (Eds.) Long distance transport and welfare of farm animals. Oxfordshir: CABI International, 2008. P.157-181.

BRYER, P.J.; SUTHERLAND, M.; DAVIS, B.L.; SMITH, J.F.; MCGLONE, J.J. The effect transport and space allowance on the physiology of breeding age gilts. Livestock

Science, v.137, p.58-65, 2011.
CHAI, J.; XIONGA, Q.; ZHANG, C.X.; MIAO, W; LI, F.E; ZHENG, R.; PENG, J.; JIANG, S.W. Effect of pre-slaughter transport plant on blood constituents and meat quality in halothane genotype of NN Large WhitexLandrace pigs. Livestock Science, v.127, p. 211-217, 2010.

COOAGRIL. Institucional. Disponível em:

<http://www.cooagril.com.br/historico.a sp>. Acesso em: 28 maio 2012.

CORASSA, A.; KOMIYAMA, C.M.; PEREIRA, T.L.; SILVA, R.S.

Caracterização do manejo pré-abate de suínos na região de Sinop - MT.

Revista Agrarian, v.6, n.22, p.479-485, 2013.

DALLA COSTA, O. A.; LUDKE, J.V.; COSTA, M.J.R.P; FAUCITANO, L., PELOSO, J.V.; DALLA ROZA, D. Efeito das condições pré-abate sobre a qualidade da carne de suínos pesados.

Revista Archivos Zootecnia, v.59, n.227, p.391- 402, 2010.

EUROPEAN CONVENTION - EC. Council Regulation n.1/2005: On the protection of animals during transport and related operations and amending Directives 64/432/EEC and 93/119/EC and Regulation (EC) No 1255/97.

Official Journal of the European Union, L 3, 22/12/2004, p.0001-0044, 2005.

GEBRESENBET, G.; BOSONA, T.G.; LJUNGBERG, D.; ARADOM, S.

OPTIMIZATION analysis of large and small-scale slaughterhouses in relation to animal transport and meatdistribution. Australian Journal of Agriculture Engineering, v.2, p.3139, 2011. 
Rev. Bras. Saúde Prod. Anim., Salvador, v.15, n.4, p.970-982 out./dez., 2014 http://www.rbspa.ufba.br ISSN 15199940

GONZÁLEZ, M.; AVERÓS, X.; VALDELVIRA, J.J; HERRANZ, A. Influence of season, distance and mixed loads on the physical and carcass integrity of pigs transported to slaughter. Meat Science, v.73, p.553- 558, 2006.

HALEY, C.; DEWEY, C.E.; WIDOWSKI, T.; POLJAK, Z.; FRIENDSHIP, R. Factors associated with in-transit losses of market hogs in Ontario in 2001.Canadian Journal of Veterinary Research, v.72, p.377-384, 2008

HERRERA, M.B.; SPILSBURY, M. AL.; TRUJILLO ORTEGA, M.E., I.; GUERRERO-LEGARRETA, R.; RAMÍREZ-NECOECHEA, P.; ROLDAN-SANTIAGO, M.; PÉREZSATO, E.; SONÍ-GUILLERMO, D.; MOTA-ROJAS. Changes in blood constituents of swine transported for 8 or $16 \mathrm{~h}$ to an Abattoir. Meat Science, v.86, p.945-948, 2010.

KEEDI, S. Transporte, unitização e seguros internacionais de carga. São Paulo: Samir Keedi, 2011. 17p.

Disponível em: $<$ http://www.multieditoras.com.br/produt o/PDF/500775.pdf>. Acesso em: 18 abr. 2013.

KEPHART, K.B.; HARPER, M.T.; RAINES, C.R. Observations of market pigs following transport to a packing plant. Journal Animal Science, v.88, p.2199-2203, 2010.

LUDTKE, J.V.; DALLA COSTA, O.A.; ROÇA, R.O.; SILVEIRA, E.T.F.; NATÁLIA, B.A.; ARAÚJO, A.P. de; MELLO JÚNIOR, A. de; AZAMBUJA, N.C. de. Bem-estar animal no manejo pré-abate e a influência na qualidade da carne suína e nos parâmetros fisiológicos do estresse. Ciência Rural, v.42, n.3, p.532-537, 2012.
MACHADO, S.T.; SANTOS, R.C.; CALDAR, F.R.; GONÇALVES, M.C.; JORDAN, R.A.; REIS, J.G.M. Operação de transporte e tempo de descanso na incidência de carne PSE em suínos. Revista Brasileira de Engenharia Agrícola e Ambiental, v.18, n.10, p.1065-1071, 2014.

MIRANDA-DE LA LAMA, G.C.; VILLARROEL, M.; MARÍA, G.A. Livestock transport from the perspective of the pre-slaugter logist chain: a review. Meat Science, v.98, p.9-20, 2014.

MOTA-ROJAS, D.; BECERRILHERRERA, M.; LEMUS, C.;

SANCHEZ, P.;GONZALEZ, M.; OLMOS, S.A.; RAMIREZ, R.; ALONSO-SPILSBURY, M. Effects of mid-summer transport duration on preand post-slaughter performance and pork quality in Mexico. Meat Science, v.73, p.404-412, 2006.

OCHOVE, V.C.C.; CARAMORI JUNIOR, J.G.; CORREA, G.S.S.; BERTOLONI, W.; ROÇA, R.O.; SILVA, G.S.; CRUZ, R.A.S.Influência da distância no bem-estar e qualidade de carne de suínos transportados em Mato Grosso. Revista Brasileira Saúde e Produção Animal [online], v.11, n.4, p.1117-1126, 2010.

RONCHI, R.D.C.; MOURA, G.A.;ROCHA, C.H. Mensuração do custo social subjacente à atualfrota autônoma de caminhões da agropecuária nacional- um estudo de caso: soja, café e boi em pé. Journal of Transport, v.7, n.2, p.52-57, 2013.

SCHWARTZKOPF-GENSWEIN, K. S; FAUCITANO, L.; DADGAR, S.;

SHAND, P.; GONZÁLEZ, L.A.;

CROWE, T.G. Road transport of cattle, swine and poultry in North America and 
Rev. Bras. Saúde Prod. Anim., Salvador, v.15, n.4, p.970-982 out./dez., 2014 http://www.rbspa.ufba.br ISSN 15199940

its impact on animal welfare, carcass and meat quality: A review. Meat

Science, v.92, p.227-243, 2012.

SUTHERLAND, M.A.; MCDONALD, A.; MCGLONE, J.J. Environmental, trailer, and gender effects on the percentage of dead and non-ambulatory pigs during transport.Veterinary Record, v.165, p.13-18, 2009.

UNIVERSIDADE FEDERAL DE VIÇOSA - UFV. Sistema de Análises Estatísticas e Genéticas - SAEG. Viçosa, MG, 1999.

WERNER, C.; REINERS,K.; WICKE, M. Short as well as long transport duration can affect the welfare of slaughter pigs. Animal Welfare, v.16, p.385-389, 2007.

WESCHENFELDER, A.V.; TORREY, S.; DEVILLERS, N.; CROWE, T.; BASSOLS, A.; SACO, Y.; PIÑEIRO, M.; SAUCIER, L.; FAUCITANO, L. Effects of trailer design on animal welfare parameters and carcass and meat quality of three Pietrain crosses being transported over a short distance. Livestock Science, v.157, p.234-244, 2013.

Data de recebimento: 04/04/2014

Data de aprovação: 10/11/2014 